UDC [616-039.71: 578.834.1] (476)

DOI: $10.21668 /$ health.risk/2021.3.01.eng

Research article

\title{
ADHERENCE TO VACCINATION AND PERCEPTION OF COVID-19 RISK AMONG POPULAITON IN THE REPUBLIC OF BELARUS
}

\author{
E.A. Hutsich, S.I. Sychyk, S.L. Itpayeva-Liudchyk \\ Scientific practical centre of hygiene, 8 Akademicheskaya Str., Minsk, 220012, Republic of Belarus
}

Our research goal was to examine health risk perception and adherence to vaccination against COVID-19 among various social and demographic population groups in Belarus.

To achieve this goal, a cross-sectional study was accomplished via using an online poll. The obtained results reveal that perception of health risks caused by COVID-19 is quite significant among people living in Belarus since only $9.9 \%$ of the questioned do not consider COVID-19 a dangerous disease. Higher levels of risk perception have been detected among medical personnel, older age groups, and people with chronic pathologies.

Most respondents believe vaccination is among the most efficient anti-COVID-19 measures; however, people are rather poorly aware about provided opportunities to get vaccinated. $33.6 \%$ among respondents who are not vaccinated don't plan to do it with; their basic reasons for this refusal are lack of trust, both in vaccines being safe and efficient and overall trust in preparations suggested for vaccination. Having analyzed answers given by respondents who were medical workers we revealed that a greater share of them were vaccinated but reasons for refusing from vaccination were the same. $20.1 \%$ respondents from all groups and $21.2 \%$ medical workers who took part in the questioning stated that they needed additional information about vaccination.

When developing communication strategies aimed at raising awareness among population, we should bear in mind that lower perception of COVID-19-related health risks and refusal from vaccination are more widely spread among people younger than 40; people who don't have higher education; people with minor children in their families. Prevalence of lower COVID-19-related health risk perception is also greater among men; people who don't live in the capital; people with elderly relatives in their families. Internet resources, data provided by the WHO and Public Healthcare Ministry, and medical personnel are considered the most reliable sources of information by population in Belarus.

Key words: poll, coronavirus, COVID-19, pandemic, risk perception, vaccination, hesitation regarding vaccination, social and demographic factors, population awareness, population health.

According to data provided by the World Health Organization (hereinafter WHO), a new coronavirus infection (COVID-19) caused more than 194 million disease cases including more than 4 million deaths over one and a half years that have passed since the first case was registered in Wuhan, China. Despite all strict quarantine measures introduced in many countries all over the world, COVID-19 morbidity has started to grow again after a short-term fall. In Belarus 440,708 disease cases have been confirmed with laboratory tests over the whole registration period and 9,934 among them were deaths; a number of daily registered disease cases remains stably high (according to data as of July 26, 2021) [1].

This ongoing COVID-19 pandemic in spite of all strict quarantine measures indicates that wide-scale vaccination is required; given that, development and implementation of ef-

(C) Hutsich E.A., Sychyk S.I., Itpayeva-Liudchyk S.L., 2021

Katsiaryna A. Hutsich - Head of Occupational Hygiene Laboratory (e-mail: ekhutsich@gmail.com; tel.: +375 17 378-80-56, +375 29 694-06-18; ORCID: https://orcid.org/0000-0002-1910-6556).

Sergey I. Sychik - Candidate of Medical Sciences, Associate Professor, Director (e-mail: rspch@rspch.by; tel.: +375 17 347-73-70; ORCID: https://orcid.org/0000-0002-5493-9799).

Sviatlana L. Itpayeva-Liudchyk - Candidate of Medical Sciences, Scientific Secretary (e-mail: itpaeva.ludchik@gmail.com; tel.: +375 17 320-02-17; ORCID: https://orcid.org/0000-0002-4878-2246). 
fective vaccines is considered among the most promising strategies to overcome the pandemic [2]. According to some data, frequency of COVID-19 contagion may start to decline just as a share of people with acquired immunity to SARS-CoV-2 will go above $67 \%$ in a given population [3]. However vaccination rates remain too slow in many countries worldwide. On July 25, $2021672,114,822$ people worldwide were completely vaccinated; $1,435,332,186$ people got one vaccination dose [1]. As it was stated by the WHO Regional European director, average number of people covered by vaccination in Europe amounted to only $24 \%$ in spite of recommended $80 \%$ [4]. In Belarus, 753,276 people got both vaccination doses (8.1\% of the total population); $1,240,581$ people got one vaccination dose $(13.3 \%$ of the total population) [1].

Vaccine availability, capabilities of a public healthcare system to organize a vaccination campaign, etc., are among significant factors influencing vaccination rates. However, certain population groups remain hesitant regarding vaccination against COVID-19 and it is another serious problem for public healthcare in many countries [5-11]. "Vaccine hesitancy" is seen by the WHO as one of ten basic threats to global health [12]. Given that, it seems extremely vital to examine factors that determine motivation to get vaccinated against COVID-19 [13].

How a person perceives a risk of a communicable disease is a most significant indicator that determines a person's attitudes towards vaccination; this indicator, in its turn, depends on multiple individual, social, and cultural factors that, among other things, can have national peculiarities. The aforementioned should be kept in mind when mass vaccination programs are developed and implemented [14, 15].

Therefore, vaccination against COVID-19 is a first-priority task to be solved by public healthcare; development of effective vaccination strategies requires national surveys that include complex studies on influence exerted by socio-demographic factors on adherence to vaccination among various population groups, a level of awareness, monitoring over trust in vaccination efficiency and better insight and assessment of how population perceives COVID-19 risks.

Our research goal was to examine health risk perception and adherence to vaccination against COVID-19 in various socio-demographic population groups in Belarus.

Data and methods. To achieve the research goal, we performed a cross-sectional study by using an online poll. The online poll was accomplished by filling in a specifically designed questionnaire made up of 26 questions and placed on the official web-site of the Scientific Practical Centre of Hygiene.

The questioning included social and demographic profiles of respondents (age, sex, marital status and family members, a place and a region of living, education, job, and activity sphere); questions regarding health including chronic diseases and COVID-19 in case history and probable reasons for contagion; questions related to perceiving health risks of COVID-19 (how dangerous the disease was for a person and other people, a probability to get infected during next 6 months); questions on priority of various prevention activities regarding COVID-19, awareness about vaccination and authority of different sources that provided information about vaccines; questions about factors that could influence a person's decision to get vaccinated against COVID-19, vaccination status of a respondent at that time, any reasons to refuse from vaccination, and any circumstances that could make vaccination in future possible as well as readiness to get vaccinated for a fee.

Respondents were offered a multiple choice ( 3 answer options) to answer questions about factors that made for contagion, priority prevention activities, sources of information about vaccination, factors influencing a decision to get vaccinated, reasons for refusing from vaccinations and circumstances for giving consent to it.

From May 19, 2021 to July 07, 2021 1,310 people took part in the online poll. Prior to filling in the questionnaire respondents had to confirm that they were older than 18 at that moment; they were also informed that their personal data would be used in scientific re- 
search in compliance with principles of anonymity and confidentiality.

All obtained data were statistically analyzed with STATISTICA 13 software package. Data analysis involved calculating absolute and relative frequencies. $95 \%$ confidence interval was calculated for extensive parameters according to Wilson score method and data were given as $\mathrm{P}(95 \% C I)$.

We applied Pearson's chi-square test $\chi^{2}$ to analyze influence exerted by social and demographic factors on perception of COVID-19related health risk and vaccination scope among various population groups. Respondents who had contra-indications to vaccinations were excluded when a share of non-vaccinated people was determined in a specific respondents' group. To estimate effects produced by a given factor, we calculated prevalence ratio $(P R)$ and its $95 \%$ confidence interval $(95 \% C I)$.

Research results were considered authentic and differences between parameters significant, when probability of a correct prediction was not lower than $95.5 \%(p<0.05)$.

Results and discussion. Having analyzed social and demographic profile of the sampling, we revealed the following. $67.0 \%$ respondents were women (64.4-69.4) and $33.0 \%$ were men (30.6-35.6). Most respondents, or $82.7 \%$ (80.6-84.7) were older than 31. Age distribution was as follows: people who were 20 years old and younger accounted for $1.9 \%(1.3-2.8)$; people aged $21-30,15.4 \%$ (13.5-17.4); people aged $31-40,29.6 \%(27.2-32.2)$; people aged 41-50, $26.1 \%$ (23.8-28.6); and people aged 51 and older, $27.0 \%(24.7-29.5)$.

Respondents were also asked questions about their marital status, family members, and chronic diseases in case they had any since this would help more profound analysis of socialdemographic factors that could be related to adherence to vaccination. Having analyzed the answers, we revealed that $70.7 \%(68.2-73.1)$ respondents were either married or had a life partner, 39.9\% (37.2-42.5) lived together with their under-age children, and $19.4 \%$ (17.3-21.6), with elderly relatives; $34.3 \%(31.8-36.9)$ respondents suffered from chronic diseases of the cardiovascular and respiratory system, pancreatic diabetes, or other chronic pathology; $31.3 \%$ (28.9-33.9) lived together with people who suffered from chronic diseases.

Respondents gave the following answers regarding their place of living: $60.9 \%(58.3-63.5)$ lived in the capital; $15.0 \%(13.1-17.0)$, in regional centers; $11.1 \%(9.6-13.0)$, in centers of municipal districts; $6.7 \%(5.5-8.2)$, in towns and urban settlements; and $6.3 \%$ (5.1-7.7) lived in villages and agricultural settlements.

Most respondents (85.0 \% (82.9-86.8)) had higher education and $64.8 \%(62.2-67.4)$ had white-collar job (21.4\% (19.2-23.7) were middle managers, $7.5 \%$ (6.2-9.0), senior managers); $6.3 \%$ (5.1-7.8) were blue-collar workers. Figure 1 shows respondents distribution as per their job (occupation).

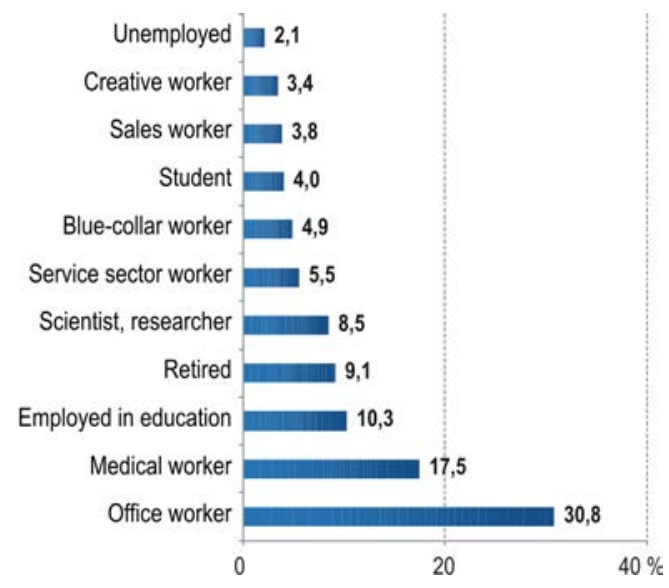

Figure 1. Respondents distributed as per job (occupation), $\%$

Questioning results revealed that $34.7 \%$ (32.2-37.4) respondents had COVID-19 in their case history that was confirmed with laboratory tests; $42.9 \%(38.4-47.5)$ out of them had asymptomatic disease or disease in its mild form, 49.2 \% (44.7-53.8) in average grave form, and $7.9 \%(5.8-10.8)$, in grave form (had to be treated in in-patient hospital). We should note that a share of people with COVID-19 in their case history was considerably higher among medical workers $(49.8 \%$ (43.4-56.2)) than among other respondents $(31.6 \%(28.8-34.4))(p<0.001)$. In respondents' opinions, there were several most significant reasons for contagion including work involving contacts with many people or medical aid provision (36.9\% (32.6-41.5)); a fam- 
ily member infected with COVID-19 (30.8\% (26.7-35.2)); the necessity to use public transport (20.4\% (17.0-24.4)); impossibility to keep safe distance from colleagues at a workplace (20.0\% (16.6-23.9)) (Figure 2).

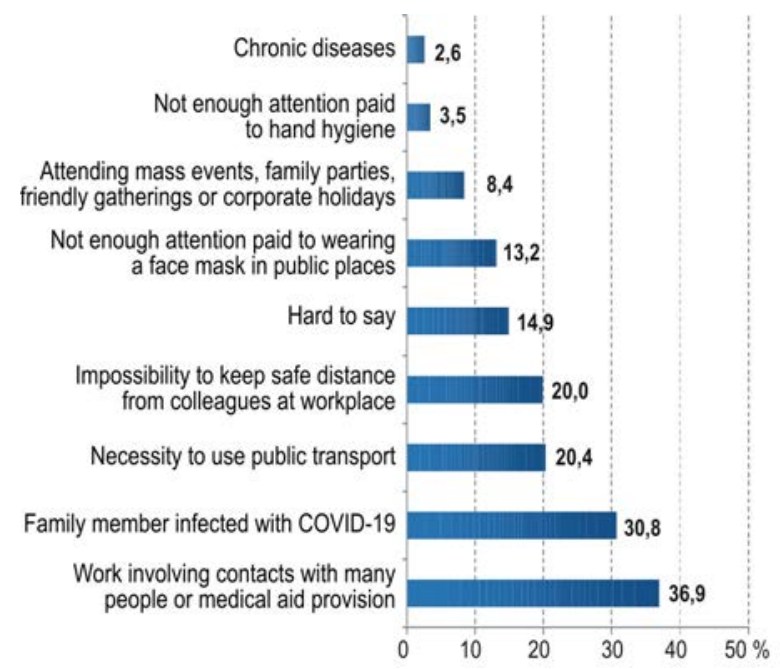

Figure 2. Respondents' answers to the question "In your opinion, what made the greatest contribution to your contagion with COVID-19?", \%

Significant factors that influence adherence to prevention activities and a decision to get vaccinated include people's perceptions of hazards caused by the disease for themselves and those around them as well as subjective estimates of how probable contagion is for them given the current epidemiologic situation (perception of health risk related to pandemic spread of the infection) $[14,16]$. Most respondents didn't think they could possibly get infected with COVID-19 during the next 6 months (46.9\% (44.3-49.7)). 37.7\% (34.0-41.6) out of them already had COVID-19 in case history, $36.9 \%(33.2-40.8)$ were vaccinated. $42.1 \%$ (39.4-44.8) respondents believed they could have the disease in its mild form during the next 6 months, and $11.0 \%(9.4-12.8)$ were afraid they could have it in its grave form.

The poll also revealed that most respondents believed COVID-19 to be dangerous both for them and for other people (78.2\% $(75.9-80.3)) ; 5.9 \%(4.7-7.3)$ thought it was dangerous only for them; $6.1 \%(4.9-7.5)$ thought it was dangerous only for others; and $9.9 \%(8.4-11.6)$ didn't see any danger at all. $83.7 \%$ (76.4-89.1) out of respondents who gave negative answers to this question didn't have COVID-19 in case history, $8.5 \%(4.8-14.6)$ had asymptomatic and mild forms, and $7.0 \%$ (3.7-12.7) were vaccinated; 78.3\% (70.4-84.5) of respondents from this groups thought they wouldn't get infected with COVID-19 during the next 6 months. Additional analysis of answers given by respondents who were medical workers revealed that they considered COVID-19 to be not dangerous much less frequently than other respondents $(6.1 \%(3.7-10.0)$ against $10.6 \%$ $(8.9-12.6)(p<0.05)$.

Most respondents believed vaccination to be among the most effective prevention measures against COVID-19 (57.9 \% (55.2-60.5). The second rank place belonged to mandatory face masks in public places $(55.9 \%(53.2-58.6)$; the third one, timely isolation of infected people and those who contacted them (54.1\% (51.4-56.8)). 51.1\% (48.4-53.8) respondents considered personal hygiene very important, $45.3 \%$ (42.7-48.1) attributed great significance to personal prevention aimed at maintaining proper immune system functioning including healthy eating habits, proper sleep, physical activity, and giving up bad habits (Figure 3).

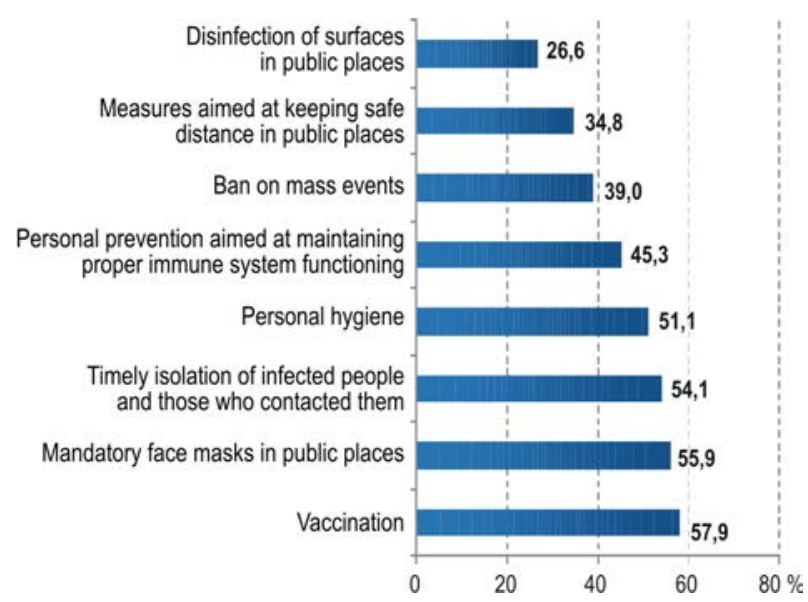

Figure 3. Respondents' answers to the question "What prevention activities against COVID-19 seem the most effective to you?", \%

People's awareness about a possibility to get vaccinated is another significant factor in any vaccination campaign. Our poll revealed that only $57.5 \%(54.8-60.1)$ respondents considered vaccine against COVID-19 to be available for all people older than 18 in Bela- 
rus.17.8 \% (15.8-20.0) respondents believed that vaccine was provided only for risk groups (medical workers, workers employed in education etc.), and $10.9 \%(9.3-12.7)$ didn't think it was possible to get vaccinated against COVID-19 in the country. $13.8 \%(12.1-15.8)$ respondents were not at all interested in vaccination against COVID-19.

The WHO experts understand that it is important to resolve issues related to infodemic which is an absence of authentic scientific data and spread of false information; it is a vital component in fight against COVID-19 pandemic [17]. Efficient communications with population require knowledge on what amount of trust people have in various sources of information. Our research revealed that most people $(60.5 \%$ (57.8-63.1)) used Internet resources to get authentic information about vaccination; data provided by the WHO and the Public Healthcare Ministry were also considered a reliable and significant source of information (Figure 4).

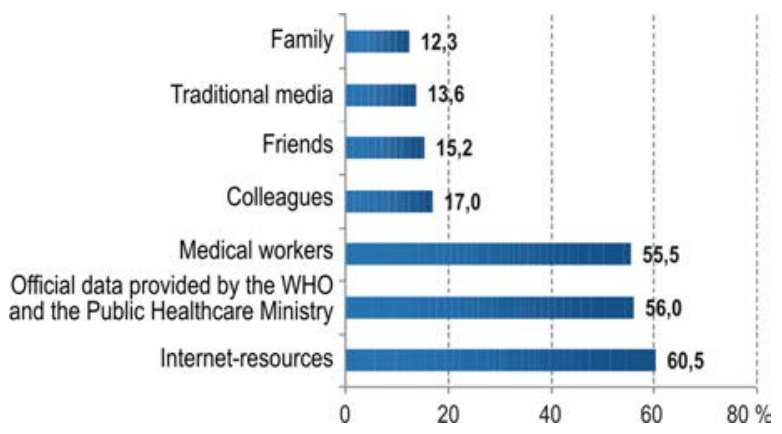

Figure 4. Respondents' answers to the question

"Which source of information about vaccination seems the most reliable to you?", \%

A decision to necessarily get vaccinated against this or that communicable disease depends on several objective and subjective factors including perception of risks related to a communicable disease (contagion probability, gravity of clinical course, possible complications and adverse outcomes), vaccine efficiency and duration of protective immunity, safety of a vaccine and any probable side effects or unfavorable reactions, trust in public healthcare organizations and vaccination campaign (medical personnel's' qualification, vaccines being stored properly etc.), availability of vaccine (location of vaccination points and their open hours), a possibility to choose a specific vaccine and to get vaccinated free of charge etc. Since vaccines against COVID-19 are being developed and implemented rather rapidly, assurance that vaccines are safe and effective might become the most significant factor among all the aforementioned ones during the current pandemic $[11,18]$. Most respondents who took part in our research mentioned several factors that were significant for them in making a decision to get vaccinated; these factors included safety of available vaccines (65.0\% (62.4-67.6)), efficiency of available vaccines $(55.0 \%(52.3-57.6))$, a possibility to choose a specific vaccine (34.9\% (32.4-37.5)), duration of protective immunity after vaccination $(34.7 \%(32.2-37.4)) .24 .8 \%(22.6-27.2)$ respondents mentioned trust in organization of vaccination campaign as a significant factor; $21.9 \%(19.8-24.3)$, a possibility to visit other countries (Figure 5).

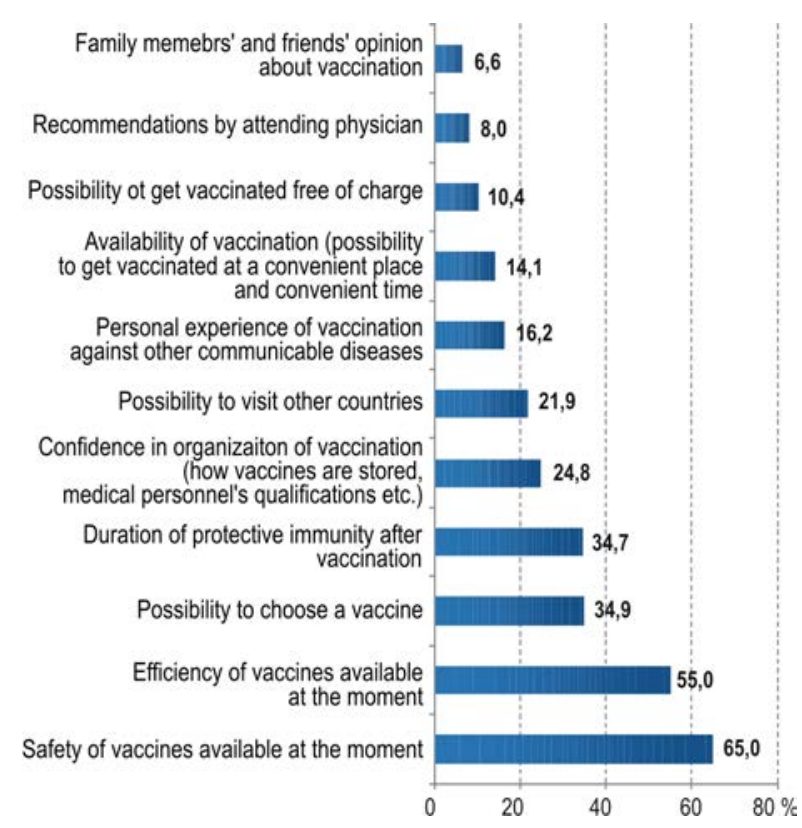

Figure 5. Respondents' answers to the question "Which factors are the most significant for you in making a decision to get vaccinated against COVID-19?”, \%

$31.9 \%$ (29.4-34.5) respondents who took part in our research were already vaccinated against COVID-19. 19.1 \% (16.6-21.8) of those who were not vaccinated planned to do it as soon as possible; $47.3 \%(44.1-50.6)$ said 
they would probably do it a bit later; $33.6 \%$ (30.6-36.8) stated they were not going to get vaccinated against COVID-19. There were several reasons why people refused from vaccination (were not vaccinated, were not going to, or were going to do it later); the first rank place belonged to absence of any confidence a vaccine was safe (people tended to believe that side effects and unfavorable reactions were highly probable $) \quad(64.4 \%(60.8-67.8))$; the second rank place belonged to absence of confidence in vaccines available at the moment (52.4\% (48.7-56.0)); it was followed by absence of confidence that a vaccine was effective (people believed that a vaccine created only weak and rather short-term protective immunity) (39.2\% (35.7-42.8)). $20.1 \%(17.3-23.2)$ respondents said they needed additional information about vaccination and another $15.4 \%$ (12.9-18.2) were against any vaccination as a way to prevent communicable diseases (Figure 6).

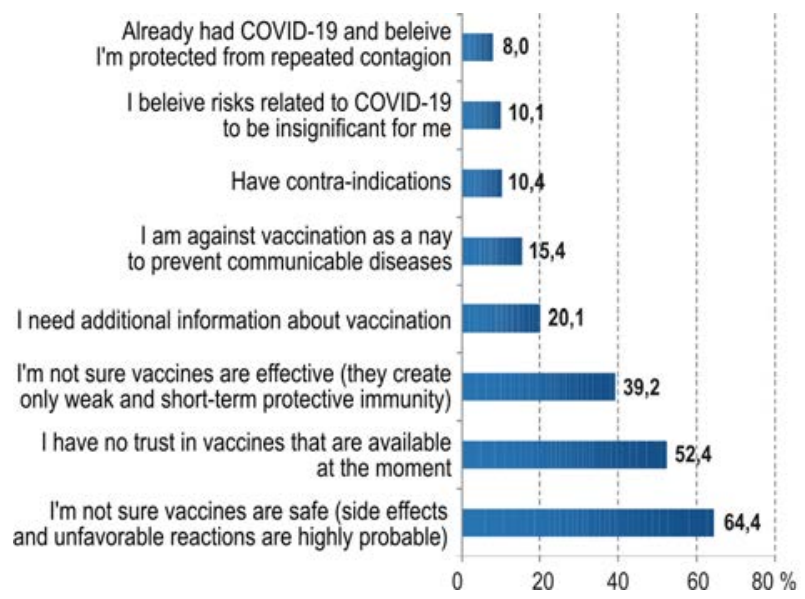

Figure 6. Respondents' answers to the question

"Why do you refuse to get vaccinated against COVID-19?", \%

Medical workers are a risk group when it comes down to COVID-19 contagion and a priority group for vaccination. Apart from a significant role that belongs to this group in the epidemiologic process of the virus spread, medical workers are a vital source of information about COVID-19 prevention and vaccination. Therefore, their knowledge and communicative skills are extremely important for gaining people's trust and persuading them to get vaccinated [13]. A share of vaccinated peo- ple was significantly higher among medical workers who took part in our research against people who was employed in other spheres, $45.4 \%(39.1-51.9)$ and $29.1 \%(26.4-31.8)$ accordingly $(p<0.001)$. Medical workers who were not vaccinated, planned to do it later or were not going to do it at all mentioned the following most frequent reasons for refusal: they had no confidence in vaccines available at the moment $(56,6 \%(47.4-65.4))$; they didn't believe vaccines were safe (considered side effects and unfavorable reactions to be highly probable) (53.1 \% (44.0-62.1); they also didn't think vaccines were effective (believed that vaccines created only weak and short-term protective immunity) (40.7\% (32.1-49.9)). 21.2\% (14.7-29.7) medical workers out of those who took part in the research stated that they needed additional information about vaccination.

A share of vaccinated among retired people was also significantly higher than among other groups (43.5 \% (34.6-52.9) $(p<0.05)$.

There was a question about circumstances that could persuade those refusing from vaccination to use this prevention measure. The answers were as follows: $59.3 \%(55.7-62.8)$ respondents needed additional scientific data on vaccines being safe and effective; $50.4 \%$ (46.8-54.1) were ready to get vaccinated in case they could select from a variety of vaccines; $18.6 \%$ (15.9-21.6) mentioned visits to other countries as a key factor in their decision-making; and $20.8 \%$ (18.0-23.9) were not ready to get vaccinated in the nearest future under any circumstances (Figure 7).

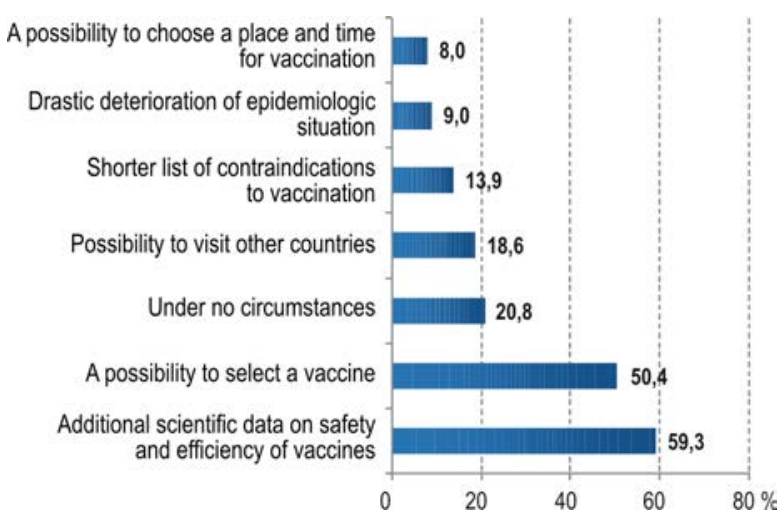

Figure 7. Respondents' answers to the question "Under what circumstances would you be ready to get vaccinated against COVID-19?", \% 
Table

Influence exerted by social-demographic factors on perception of COVID-19-related health risks and vaccination scope

\begin{tabular}{|c|c|c|c|c|c|}
\hline No. & Analyzed factors & $\begin{array}{l}\text { A share of people who } \\
\text { believe COVID-19 is a } \\
\text { dangerous disease, } \%\end{array}$ & $P R$ & $\begin{array}{l}\text { A share of vacci- } \\
\text { nated respon- } \\
\text { dents, } \% \\
\end{array}$ & $P R$ \\
\hline 1 & $\begin{array}{l}\text { Age: } \\
\text { - younger than } 40 \text { (40 included }) \\
\text { - older than } 40\end{array}$ & $\begin{array}{c}88.0(85.1-90.3) \\
92.1(89.9-93.9)^{*}\end{array}$ & $\begin{array}{c}1.53 \\
(1.10-2.13)\end{array}$ & \begin{tabular}{|}
$29.1(25.6-32.9)$ \\
$38.1(34.5-41.9)^{*}$ \\
\end{tabular} & $\begin{array}{c}1.14 \\
(1.06-1.24)\end{array}$ \\
\hline 2 & $\begin{array}{l}\text { Sex: } \\
- \text { men } \\
- \text { women }\end{array}$ & $\begin{array}{c}87.1(83.6-89.9) \\
91.7(89.7-93.3)^{*}\end{array}$ & $\begin{array}{c}1.55 \\
(1.12-2.16)\end{array}$ & $\begin{array}{l}31.7(27.5-36.3) \\
35.0(31.8-38.3)\end{array}$ & - \\
\hline 3 & $\begin{array}{l}\text { Marital status: } \\
\text { - married / have a life partner } \\
\text { - single / do not have a life partner }\end{array}$ & $\begin{array}{l}89.6(87.5-91.4) \\
91.4(88.2-93.8)\end{array}$ & - & $\begin{array}{l}35.1(32.0-38.3) \\
30.9(26.4-35.9)\end{array}$ & - \\
\hline 4 & $\begin{array}{l}\text { Place of living: } \\
\text { - capital/regional center } \\
\text { - other settlement }\end{array}$ & $\begin{array}{l}90.9(88.9-92.5) \\
88.0(83.9-91.1)\end{array}$ & - & $\begin{array}{l}35.1(32.1-38.2) \\
30.0(25.1-35.4)\end{array}$ & - \\
\hline 5 & $\begin{array}{l}\text { Region of living: } \\
\text { - Minsk } \\
\text { - other settlement }\end{array}$ & $\begin{array}{c}92.2(90.1-93.8) \\
87.1(83.9-89.7)^{*}\end{array}$ & $\begin{array}{c}1.65 \\
(1.19-2.29)\end{array}$ & $\begin{array}{l}33.8(30.5-37.3) \\
33.9(29.8-38.2)\end{array}$ & - \\
\hline 6 & $\begin{array}{l}\text { Education: } \\
\text { - high } \\
\text { - secondary/vocational/specialized secon- } \\
\text { dary education }\end{array}$ & $\begin{array}{l}91.1(89.3-92.6) \\
84.8(79.1-89.1)^{*}\end{array}$ & $\begin{array}{c}1.71 \\
(1.17-2.50)\end{array}$ & $\begin{array}{l}35.5(32.7-38.4) \\
24.5(18.8-31.2)^{*}\end{array}$ & $\begin{array}{c}1.17 \\
(1.07-1.29)\end{array}$ \\
\hline 7 & $\begin{array}{l}\text { Job hierarchy: } \\
\text { - top manager/middle manager } \\
\text { - expert/office clerk/worker } \\
\end{array}$ & $\begin{array}{l}87.8(84.2-90.8) \\
91.1(89.1-92.8) \\
\end{array}$ & - & $\begin{array}{l}34.2(29.5-39.2) \\
33.7(30.7-36.9) \\
\end{array}$ & - \\
\hline 8 & $\begin{array}{l}\text { Chronic diseases in case history: } \\
- \text { yes } \\
\text { - no }\end{array}$ & $\begin{array}{c}93.8(91.1-95.7) \\
88.3(86.0-90.3)^{*}\end{array}$ & $\begin{array}{c}1.88 \\
(1.26-2.81)\end{array}$ & $\begin{array}{c}37.7(33.1-42.6) \\
32.0(29.0-35.3)^{*} \\
\end{array}$ & $\begin{array}{c}1.18 \\
(1.00-1.38)\end{array}$ \\
\hline 9 & $\begin{array}{l}\text { Underage children in a family (live together): } \\
- \text { yes } \\
\text { - no }\end{array}$ & $\begin{array}{c}86.4(83.2-89.1) \\
92.6(90.6-94.3)^{*}\end{array}$ & $\begin{array}{c}1.85 \\
(1.33-2.57)\end{array}$ & \begin{tabular}{|}
$30.5(26.6-34.7)$ \\
$36.2(32.8-39.7)^{*}$ \\
\end{tabular} & $\begin{array}{c}1.09 \\
(1.01-1.18)\end{array}$ \\
\hline 10 & $\begin{array}{l}\text { Elderly people in a family (live together): } \\
- \text { yes } \\
\text { - no }\end{array}$ & $\begin{array}{c}85.8(81.0-89.6) \\
91.2(89.3-92.8)^{*}\end{array}$ & $\begin{array}{c}1.61 \\
(1.12-2.31)\end{array}$ & $\begin{array}{l}37.3(31.5-43.6) \\
33.0(30.2-36.0) \\
\end{array}$ & - \\
\hline 11 & $\begin{array}{l}\text { People with chronic diseases in a family } \\
\text { (live together): } \\
\text { - yes } \\
\text { - no }\end{array}$ & $\begin{array}{c}93.2(90.3-95.2) \\
88.8(86.6-90.7)^{*}\end{array}$ & $\begin{array}{c}1.64 \\
(1.10-2.46)\end{array}$ & $\begin{array}{l}37.5(32.8-42.5) \\
32.3(29.2-35.5)\end{array}$ & - \\
\hline
\end{tabular}

$\mathrm{N}$ o t e : * man differences are statistically significant at $p<0.05$.

As for respondents being ready to get vaccinated for a fee, our research revealed that $9.3 \%$ (7.9-11.0) were ready to pay for vaccination against COVID-19 in future; $58.9 \%$ (56.2-61.5) were ready to pay provided there was a wide selection of vaccines they could choose from; $31.8 \%(29.4-34.4)$ were not ready to get vaccinated for a fee.

Table contains results obtained through analyzing relations between social-demographic factors and perception of COVID-19related health risks and adherence to vaccination.
Given that the gravest COVID-19 forms including those with lethal outcomes usually occur among elderly people, this population group is considered to be priority one for vaccination. Therefore, it seems interesting to examine how age and sex influence health risks and adherence to vaccination against COVID-19 since it helps develop more efficient national strategies of vaccination campaigns [19]. Results obtained in several studies indicate that elderly age and female sex might be associated with greater perception of risks related to COVID-19 contagion and lethal outcome due 
to the disease [11, 20-22]. Our research results revealed a higher share of people who thought COVID-19 was a dangerous disease among respondents older than $40(p<0.05)$, and refuses form vaccination were by 1.14 (1.06-1.24) times more frequent among people younger than 40 than in the older age group. Additional analysis of risk perception by people older than 50 allowed establishing that a share of respondents older than 50 who considered COVID-19 to be a dangerous disease was considerably higher than among younger people (95.5\% (92.8-97.2) and 88.2\% (86.0-90.1) accordingly) $(p<0.001)(P R 2.62(1.57-4.35))$. We should note that having an elderly relative in a family had an inverse influence on risk perception since a share of people who thought COVID-19 to be a dangerous disease was significantly lower among people living with their elderly relatives than among respondents who didn't have elderly relatives in a family (85.8 \% (81.0-89.6) and 91.2\% (89.3-92.8) accordingly) $(p<0.01)(P R 1.61(1.12-2.31))$. Underage children in a family were also a factor that caused lower risk perception ( $P R \quad 1.85$ (1.33-2.57)) and adherence to vaccination against COVID-19 (PR 1.09 (1.01-1.18)). Our research results revealed that women tended to have greater perception of COVID-19-related risks ( $P R 1.55$ (1.12-2.16)).

Education may be a rather contradictory factor regarding vaccination. People with higher education tend to be better aware and have greater health risk perception; however, higher education may be associated with refusal from vaccination due to selective use of information about it $[10,18]$. Our research established that a share of people who believed COVID-19 was a dangerous disease was higher among respondents with higher education than among those who didn't have it (91.1\% (89.3-92.6) and 84.8\% (79.1-89.1) accordingly) $(p<0.01)$ (PR $1.71(1.17-2.50))$. Refusals form vaccination were 1.17 (1.07-1.29) times more frequent among people who didn't have higher education.

We analyzed how risk perception changed depending on a place of living and established that respondents who lived in the capital (Minsk) had greater perception of COVID-19-related risks than those who lived in other settlements in the country $(92.2 \%(90.1-93.8)$ and $87.1 \%$ (83.9-89.7) accordingly) $(p<0.01)(P R \quad 1.65$ (1.19-2.29)).

According to data obtained in research accomplished in several European countries and the USA people with chronic pathologies refuse from vaccination much rarer and are more likely to follow recommendations on how to protect their health from COVID-19 since they feel themselves too vulnerable due to additional health risk factors [22, 23]. Our research results indicated that a chronic disease in case history was a predictor of greater COVID-19 risk perception (PR $1.88(1.26-2.81))$ and greater adherence to vaccination as well ( $P R \quad 1.18(1.00-1.38)$ ). Besides, a share of people who thought COVID-19 to be a dangerous disease was significantly higher among respondents who lived with relatives suffering from chronic pathology than among those who didn't have any relatives with chronic diseases in their family (93.2\% (90.3-95.2) and 88.8 \% (86.6-90.7) accordingly) $(p<0.001)(P R 1.64(1.10-2.46))$.

Conclusions. The present research indicates that perception of COVID-19-related health risk is quite high among people living in Belarus since only $9.9 \%$ respondents don't consider COVID-19 to be a dangerous disease; most of them have already had the infection, either asymptomatic or in mild form, or are vaccinated. Greater risk perception among medical workers and other priority risk groups (elderly people and people with chronic pathologies) is another positive fact.

Most respondents who took part in the online poll believe that vaccination is among the most effective prevention measures against COVID-19 (57.9 \%); however, people are rather poorly aware about possibilities to get vaccinated: only $57.5 \%$ respondents know that in Belarus vaccination is available to all people older than 18 .

$33.6 \%$ out of respondents who are not vaccinated are not going to do it and primary reasons for this refusal are absence of confidence that vaccines are safe and effective and absence of confidence in available vaccines, 
and $20.1 \%$ people also state they need additional information about vaccination. Analysis of answers given by medical workers indicates that a share of vaccinated people is higher among them but reasons for refusal from vaccination are the same. $21.2 \%$ medical workers who took part in the poll stated they needed additional information about vaccination.

The research results indicate that widerscale information campaigns are necessary to spread scientifically grounded and authentic information about COVID-19 including data on safety and efficiency of vaccines. Since medical workers are a reliable and important source of information and given their insufficient awareness, it is necessary to take efforts to improve medical workers' knowledge about vaccination against COVID-19 and their communicative skills required to motivate their patients to get vaccinated.

When developing strategies aimed at raising population awareness, it should be kept in mind that lower risk perception regarding COVID-19 and higher prevalence of refusals from vaccinations are much more typical for people who are younger than 40; people without higher education; people with underage children in their family. Lower perception of COVID-19-related risks is also more frequent among men who live beyond the capital; people who have elderly relatives living with them. Internet-resources and data provided by the WHO and Public Healthcare Ministry as well as by medical workers are the most trusted sources of information for population.

Our research results can be applied to plan, implement, and assess efficiency of the national strategy aimed at vaccine prevention of COVID-19 in Belarus as well as to detect tendencies in health risk perception, knowledge, public trust and population adherence to vaccination as a priority trend in COVID-19 prevention.

Funding. The research has been accomplished due to use of funds belonging to the Scientific Practical Centre of Hygiene.

Conflict of interests. The authors declare there is no any conflict of interests.

\section{References}

1. WHO Coronavirus (COVID-19) Dashboard. World health organization, 2021. Available at: https://covid19.who.int/ (26.07.2021).

2. COVID-19 strategy update. World health organization, 2020. Available at: https://www.who.int/publications $/ \mathrm{m} /$ item/covid-19-strategy-update (26.07.2021).

3. Randolph H.E., Barreiro L.B. Herd Immunity: Understanding COVID-19. Immunity, 2020, vol. 52, no. 5, pp. 737-741. DOI: 10.1016/j.immuni.2020.04.012

4. Statement - COVID-19: The stakes are still high. Statement by Dr Hans Henri P. Kluge, WHO Regional Director for Europe. WHO, Regional office for Europe, 2021. Available at: https://www. euro.who.int/ru/health-topics/health-emergencies/coronavirus-covid-19/statements/statement-covid-19the-stakes-are-still-high (26.07.2021).

5. Coustasse A., Kimble C., Maxik K. COVID-19 and Vaccine Hesitancy. Journal of Ambulatory Care Management, 2021, vol. 44, no. 1. pp. 71-75. DOI: 10.1097/JAC.0000000000000360

6. Freeman D., Bao S. Loe, Chadwick A., Vaccari C., Waite F., Rosebrock L., Jenner L., Petit A. [et al.]. COVID-19 vaccine hesitancy in the UK: The Oxford coronavirus explanations, attitudes, and narratives survey (Oceans) II. Psychological Medicine, 2020, pp. 1-15. DOI: 10.1017/S0033291720005188

7. Neumann-Böhme S., Varghese N.E., Sabat I., Barros P.P., Brouwer W., van Exel J., Schreyögg J., Stargardt T. Once we have it, will we use it? A European survey on willingness to be vaccinated against COVID-19. Eur. J. Health Econ., 2020, vol. 21, no. 7, pp. 977-982. DOI: 10.1007/s10198-020-01208-6

8. Edwards B., Biddle N., Gray M., Sollis K. COVID-19 vaccine hesitancy and resistance: Correlates in a nationally representative longitudinal survey of the Australian population. PLoS One, 2021, vol. 16, no. 3, pp. e0248892. Available at: https://journals.plos.org/plosone/article?id=10.1371/journal.pone.0248892 (26.07.2021).

9. Murphy J., Vallières F., Bentall R.P., Shevlin M., McBride O., Hartman T.K., McKay R., Bennett K. [et al.]. Psychological characteristics associated with COVID-19 vaccine hesitancy and resistance in Ireland and the United Kingdom. Nature communications, 2021, vol. 12, no. 1, pp. 29. Available at: https://www.nature.com/articles/s41467-020-20226-9\#citeas (26.07.2021). 
10. Wake A.D. The Willingness to Receive COVID-19 Vaccine and Its Associated Factors: "Vaccination Refusal Could Prolong the War of This Pandemic" - A Systematic Review. Risk Management and Healthcare Policy, 2021, vol. 14, pp. 2609-2623. DOI: 10.2147/rmhp.s311074

11. Troiano G., Nardi A. Vaccine hesitancy in the era of COVID-19. Public health, 2021, vol. 194, pp. 245-251. DOI: 10.1016/j.puhe.2021.02.025

12. Ten threats to global health in 2019. WHO. Available at: https://www.who.int/ru/news$\mathrm{room} /$ spotlight/ten-threats-to-global-health-in-2019 (26.07.2021).

13. Operational guidance: acceptance and uptake of COVID-19 vaccines, January 2021. WHO Regional Office for Europe, Copenhagen, 2021, 10 p. Available at: https://apps.who.int/iris/handle/10665/338855 (26.07.2021).

14. Alqahtani M.M.J., Arnout B.A., Fadhel F.H., Sufyan N.S. Risk perceptions of COVID-19 and its impact on precautionary behavior: A qualitative study. Patient education and counseling, 2021, vol. 104, no. 8, pp. 1860-1867. DOI: 10.1016/j.pec.2021.02.025

15. Chatterjee R., Bajwa S., Dwivedi D., Kanj R., Ahammed M., Shaw R. COVID-19 Risk Assessment Tool: Dual application of risk communication and risk governance. Progress in Disaster Science, 2020, vol. 7, pp. 100109. Available at: https://www.sciencedirect.com/science/article/pii/S2590061720300466 (26.07.2021).

16. Wise T., Zbozinek T.D., Michelini G., Hagan C.C., Mobbs D. Changes in risk perception and self-reported protective behaviour during the first week of the COVID-19 pandemic in the United States. Royal Society open science, 2020, vol. 7, no. 9, pp. 200742. Available at: https://royalsocietypublishing.org/doi/10.1098/rsos.200742 (26.07.2021).

17. COVID-19 response: Resolution WHA73.1. Seventy-third World Health Assembly. Available at: https://apps.who.int/gb/ebwha/pdf_files/WHA73/A73_R1-en.pdf(26.07.2021).

18. Leng A., Maitland E., Wang S., Nicholas S., Liu R., Wang J. Individual preferences for COVID-19 vaccination in China. Vaccine, 2021, vol. 39, no. 2, pp. 247-254. DOI: 10.1016/j.vaccine. 2020.12.009

19. 20th ETAGE Meeting Report. Virtual meeting, Copenhagen, Denmark, 11-12 November 2020. Available at: https://apps.who.int/iris/bitstream/handle/10665/338559/WHO-EURO-2021-1808-4155956715-eng.pdf (26.07.2021).

20. De Bruin W.B. Age Differences in COVID-19 Risk Perceptions and Mental Health: Evidence From a National U.S. Survey Conducted in March 2020. The Journals of Gerontology, 2021, vol. 76, no. 2, pp. e24-e29. DOI: 10.1093/geronb/gbaa074

21. Barber S.J., Kim H. COVID-19 Worries and Behavior Changes in Older and Younger Men and Women. The Journals of Gerontology, 2021, vol. 76, no. 2, pp. e17-e23. DOI: 10.1093/geronb/gbaa068

22. Mansilla Domínguez J.M., Font Jiménez I., Belzunegui Eraso A., Otero D.P., Díaz Pérez D., Recio Vivas A.M. Risk Perception of COVID-19 Community Transmission among the Spanish Population. International journal of environmental research and public health, 2020, vol. 17, no. 23, pp. 8967. Available at: https://www.mdpi.com/1660-4601/17/23/8967 (26.07.2021).

23. Williams L., Gallant A.J., Rasmussen S., Brown Nicholls L.A, Cogan N., Deakin K., Young D., Flowers P. Towards intervention development to increase the uptake of COVID-19 vaccination among those at high risk: Outlining evidence-based and theoretically informed future intervention content. British Journal of Health Psychology, 2020, vol. 25, no. 4, pp. 1039-1054. DOI: 10.1111/bjhp.12468

Hutsich E.A., Sychyk S.I., Itpayeva-Liudchyk S.L. Adherence to vaccination and perception of COVID-19 risk among populaiton in the Republic of Belarus. Health Risk Analysis, 2021, no. 3, pp. 4-13. DOI: 10.21668/health.risk/2021.3.01.eng

Received: 23.08 .2021

Accepted: 20.09.2021

Published: 30.09 .2021 